\title{
Magnetic fingerprints of surface sediment in the Bohai Sea, China
}

\author{
Mingkun $\mathrm{Li}^{\mathrm{a}}$, Shanying Zhu ${ }^{\mathrm{a}}$, Tingping Ouyang ${ }^{\mathrm{a}, *}$, Jianhui Tang ${ }^{\mathrm{b}, * *}$, Chenjian $\mathrm{He}^{\mathrm{a}}$ \\ ${ }^{a}$ School of Geography, South China Normal University, Guangzhou 510631, PR China \\ ${ }^{\mathrm{b}}$ Key Laboratory of Coastal Environmental Processes and Ecological Remediation, Yantai Institute of Coastal Zone Research, Chinese Academy of Sciences, Yantai 264003, \\ PR China
}

\section{A R T I C L E I N F O}

\section{Keywords:}

Bohai Sea

Surface sediments

Magnetic properties

Provenance

\begin{abstract}
A B S T R A C T
The understanding of the surrounding river impacts on the sediment supply to the Bohai Sea, northern China, is insufficient. In this study, magnetic measurements on surface sediment from the Bohai Sea and surrounding rivers were performed to interpret the distribution and origin of sediment in the Bohai Sea. Different magnetic properties in the analyzed material correspond to seven provenance areas. The magnetic mineral content decreases gradually toward the central Bohai Sea from its marginal areas. Sediment in the central and northern parts contains higher concentrations of finer magnetic minerals than the southern Bohai Sea. The western Bohai Sea (western Bohai and Liaodong bays) has high contents of magnetic minerals because its provenance areas contain abundant old metamorphic rocks with magnetite. The Yellow River, with the most elevated sediment flux, contributes with fine, high-corercivity magnetic minerals (e.g., hematite) to the southern Bohai Sea (mainly in the northwestern Laizhou Bay). Some local rivers (e.g., Fuzhou River) are also important contributors to the coastal waters, due to the magnetic similarities. Sediment from the north Yellow Sea is magnetically similar to the Yellow River detritus. The results highlight the use of the rapid magnetic method in provenance tracing.
\end{abstract}

\section{Introduction}

Intracontinental seas surrounded by continents are connected to open oceans with straits. The seas play a significant role in terrigenous sediment dispersal since they are mainly fed with fluvial material with a composition that is affected by land weathering, human activities, oceanic circulations, and continental-oceanic interactions (Imai et al., 2006; Qiao et al., 2010; Zalasiewicz et al., 2016). The Bohai Sea in northern China, connected with the Yellow Sea by the Bohai Strait, is a nearly-closed inland sea encircled on three sides by the Liaodong Peninsula, the Northern China Plain, and the Shandong Peninsula (Fig. 1). It is composed of the Liaodong Bay, the Bohai Bay, the Laizhou Bay, the Central Basin, and the Bohai Strait (Fig. 1; Qin et al., 1985). The sea is supplied by dozens of rivers flowing through regions with disparate lithology and human activity intensities. Among these rivers, the Yellow River (Huanghe), one of the worldwide largest rivers, is thought to be the primary source of the Bohai Sea and other east China seas, especially for suspended load (Qin et al., 1985; Qiao et al., 2017). For instance, it is confirmed that the Yellow River sediment settle in the Laizhou Bay, east side of the river estuary (Fig. 1) (Li et al., 2010; Qiao et al., 2010), but numerical simulations indicate that the Yellow River is responsible for only $30 \%$ of the suspended in the northern Bohai Sea (Li et al., 2010). Thus, studying the sediment contributions from rivers of small sizes is essential for a full understanding of the sediment transport into the Bohai Sea.

Over the past decades, considerable influence from local rivers other than the Yellow River has been revealed by mineralogical and geochemical sediment compositions. As an exmaple, Chen et al. (1980) divided the Bohai Sea into several sub-provenance areas of different fluvial catchments based on detrital mineral distributions. The southeastern Laizhou Bay in the southern Bohai Sea (Fig. 1) is known to be fed by waterways along the south and east coasts, as revealed by heavy minerals, such as amphibole and epidote (K. Wang et al., 2010c). Heavy-mineral distributions indicate that the Yellow River only affects the central part of the Bohai Bay in the west, and that the northern part of the bay instead is mainly fed from the Luanhe River that enters the Bohai Sea in the northwest (Fig. 1; Han et al., 2013). In addition, Dou et al. (2014) revealed that the clay minerals in the northern Liaodong Bay in the northeastern Bohai Sea partly derive from rivers in the north, and that the western Liaodong Bay is supplied by the Luanhe River, although Hou et al. (2017) argued for a possible transport pathway from the north also for the western Liaodong Bay. Besides, Fuzhou River, a small stream entering the eastern Liaodong Bay, is proven to be a contributor there (Chen et al., 1980; Hou et al., 2017; Wang et al.,

\footnotetext{
* Corresponding author at: 55 Zhongshan Road West, Tianhe District, Guangzhou 510631, China

** Corresponding author at: 17 Chunhui Road, Laishan District, Yantai 264003, China.

E-mail addresses: oyangtp@m.scnu.edu.cn (T. Ouyang), jhtang@yic.ac.cn (J. Tang).
} 


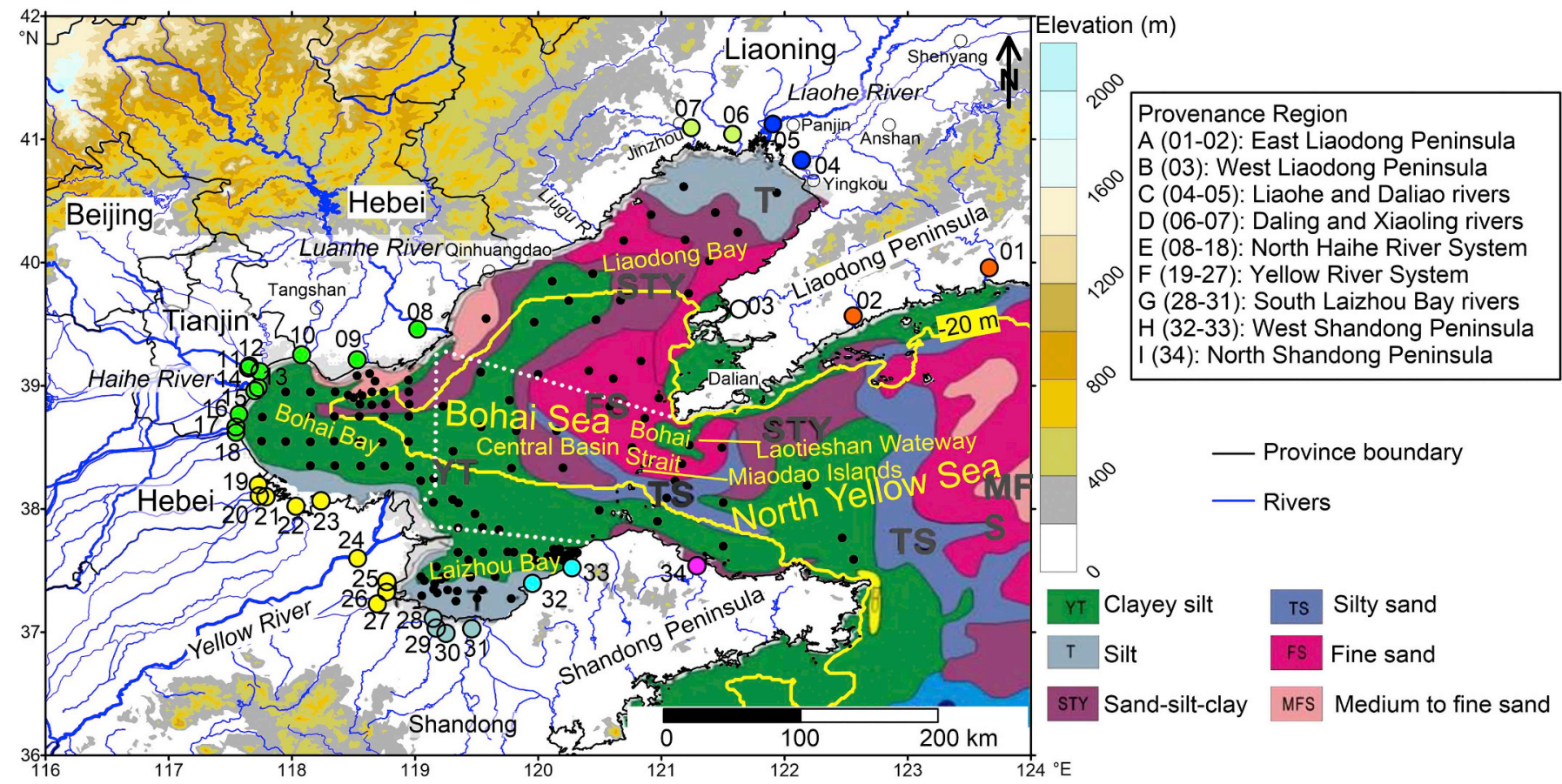

Fig. 1. Topography, sampling sites (coloured and black dots), river systems, and sediment types in the Bohai Sea and adjacent regions. Numbers represent the 34 rivers listed in Table 1. The nine potential provenance regions are marked by nine colors. The solid yellow line and white dotted lines stand for the $-20 \mathrm{~m}$ isobath and boundaries of different sea regions, respectively. The sediment types are from Liu et al., (2010). (For interpretation of the references to colour in this figure legend, the reader is referred to the web version of this article.)

2014). These previous studies only deal with parts of the Bohai Sea, and lack sediment samples from rivers that represent the source regions.

A large-scale sediment-transport perspective is possible by using mineral magnetism, a non-destructive and more rapid method than traditionally mineralogical and geochemical methods. Due to significant magnetic difference for sediment from different source areas (Caitcheon, 1993; Kissel et al., 2016, 2017; Zhang et al., 2008), magnetism is widely used to track transport of fine-grained sediments (Ellwood et al., 2006; Gamboa et al., 2017; Hatfield et al., 2013; Horng and Huh, 2011; Kim et al., 2013; Kissel et al., 2018; Wang et al., 2017; Xue et al., 2019). For instance, sediment of the Yellow-River and Yangtze-River estuaries can be distinguished by different relative contents of ferrimagnetic and anti-ferromagnetic minerals and saturation isothermal remanent magnetization (Li et al., 2012; Zhang et al., 2008). Furthermore, minerals in Iceland and Greenland sediment sources have different magnetic-crystal grain-sizes, making it possible to discriminate provenance in the northern North Atlantic Ocean (Hatfield et al., 2013). East China Sea sediment from the old Yellow River, the Yangtze River, Taiwan rivers, and Korea rivers have been distinguished by magnetic parameters and Fuzzy c-means cluster analysis (Kim et al., 2013). Variations in relative content of ferrimagnetic and anti-ferromagnetic minerals in a core indicates that the provenance in the northwest slope of South China Sea changed with time over the past 36 kyr (Li et al., 2018).

Magnetic properties for sediment from the Liaodong Bay (Wang et al., 2015), Central Bohai Sea (Wang et al., 2017), Yellow River estuary (Zhang et al., 2008), and mud area (Y. Wang et al., 2010a) has been used to discriminate different sediment sources for Bohai Sea deposits. However, the Yellow River was the only river sourcing in the Bohai Sea itself that were included in the magnetic studies, thus making the understanding of the sediment flux into the Bohai Sea incomplete.

In this study, multiple magnetic parameters of surface sediment collected from the Bohai Sea and its surrounding rivers, as well as the adjacent north Yellow Sea are presented. The results lead us to constrain the transport paths of magnetic sediment particles for the entire Bohai Sea.

\section{Regional settings}

\subsection{Physiography and sediment distributions}

The Bohai Sea, connected with the Yellow Sea by the Bohai Strait, is a nearly-closed inland sea encircled on three sides by the Liaodong Peninsula, the Northern China Plain, and the Shandong Peninsula (Fig. 1). The total area is $77,000 \mathrm{~km}^{2}$ and the average water depth is $18 \mathrm{~m}$ (Xu et al., 1997). The seabed of the three bays slope down to the central basin and the strait, and the deepest point is located in the Laotieshan Waterway with $-84 \mathrm{~m}$. (Fig. 1). The average slopes for the Liaodong, Bohai, and Laizhou bays all are $0.2 \%$. The average and deepest water depths in the Liaodong Bay are $<30 \mathrm{~m}$ and $>60 \mathrm{~m}$, respectively. Notably, the seabed of the Liaodong Shoal on the north side of Laotieshan Waterway is undulating. The Bohai Bay's maximum and mean water depths are $39 \mathrm{~m}$ and about $20 \mathrm{~m}$, respectively. The Laizhou Bay is shallower than $20 \mathrm{~m}$, with an inconspicuous underwater bank slope on the east bank. The water depth of the Bohai Central Basin ranges from 20 to $26 \mathrm{~m}$ (Xu et al., 1997). The Bohai Strait, a connection between the Bohai and Yellow seas, is about $115 \mathrm{~km}$ in width and is divided into several waterways by the Miaodao Islands (Fig. 1) (Xu et al., 1997).

A "Y- shaped" mud region filled with silt clay distributes in the central Bohai Bay, Central Basin, northern Laizhou Bay, and extends to the Yellow Sea along the south coast (Liu et al., 2010; Qiao et al., 2017). Coast shoals in southern Laizhou Bay, south Bohai Bay, and northern Liaodong Bay are covered by silt. However, sediments in the north Bohai Bay, and the east and west sides of Liaodong Bay are medium to fine sand, and fine sand. Sand-silt-clay sediments distribute in the periphery of mud region. Fine sand and silty sand distribute in areas close to the central and northern Bohai Strait.

\subsection{Catchment geology and hydrography of the Bohai Sea}

Except for rivers close to Qinhuangdao, such as the Liugu River that in the western Liaodong Bay, almost sediment samples covering all 
Table 1

General characteristics of rivers flowing into the Bohai Sea.

\begin{tabular}{|c|c|c|c|c|c|c|c|}
\hline River No. & River name & Length (km) & Area $\left(\mathrm{km}^{2}\right)$ & Water discharge $\left(10^{8} \mathrm{~m}^{3} / \mathrm{a}\right)$ & Sediment load $\left(10^{4} \mathrm{t} / \mathrm{a}\right)$ & Duration & References \\
\hline 01 & Dayang & 230 & 1968.4 & 31 & 12.58 & / & Zhang, 2000 \\
\hline 02 & Biliu & 165 & 2848 & 3.78 & 13.21 & $1956-2000$ & Yang, 2011 \\
\hline 03 & Fuzhou & 133.7 & 1593 & 1.37 & 16.8 & / & Chen et al., 1998 \\
\hline 04 & Daliao & 97 & 1962 & 43.62 & 193.66 & $1963-2007$ & H. Wang, 2010 \\
\hline 05 & Liao & 1396 & $12.64 \times 10^{4}$ & 31.29 & 1420 & 1954-2015 & MWRC, 2019 \\
\hline 06 & Daling & 397 & 23,549 & 19.63 & 2740 & / & Chen et al., 1998 \\
\hline 07 & Xiaoling & 397.4 & 23,549 & 4.03 & 364 & / & Chen et al., 1998 \\
\hline 08 & Luanhe & 877 & $4.49 \times 10^{4}$ & 46.51 & 1739 & 1950-1984 & Chen et al., 1998 \\
\hline 09 & Xiaoqinglong & 75 & 383 & / & / & / & / \\
\hline 10 & Dou & 121.4 & 1340 & 13.10 & 12.1 & / & Chen et al., 1998 \\
\hline 11 & Chaobai & 458 & 14.8 & 7.30 & 7.30 & 1973-1997 & Lei et al., 2007 \\
\hline 12 & Yongding & $>740$ & $5.08 \times 10^{4}$ & 0.85 & 1.71 & 1973-1997 & Lei et al., 2007 \\
\hline 13 & Jiyun & 144.54 & $1.1 \times 10^{4}$ & 6.45 & 6.81 & $1973-1997$ & Lei et al., 2007 \\
\hline 14 & Haihe & 1036 & $8.4 \times 10^{4}$ & 7.921 & 2540 & 1960-2015 & MWRC, 2019 \\
\hline 15 & Dagu & 80.5 & / & / & / & / & / \\
\hline 16 & Beipaihe & 143.8 & 1328 & 0.93 & 2.67 & / & Chen et al., 1998 \\
\hline 17 & Duliujian & 67 & 511 & 10.2 & / & 1950-1999 & Lei et al., 2007 \\
\hline 18 & Ziya New & 143.4 & 5200 & 3.09 & 38.6 & / & Chen et al., 1998 \\
\hline 19 & Xuanhui & 169.7 & 3031 & 0.44 & 4.24 & / & Chen et al., 1998 \\
\hline 20 & Zhangweixin & 202.7 & $3.70 \times 10^{4}$ & 1.32 & Silted & $1973-2003$ & Yu, 2004 \\
\hline 21 & Majia & 448 & $12,239.2$ & 2.93 & 76.2 & / & Chen et al., 1998 \\
\hline 22 & Tuhai & 446.5 & 1368 & 8.97 & 157 & / & Chen et al., 1998 \\
\hline 23 & Chao & 73.5 & 11,408 & / & / & / & Zhao and Yu, 2019 \\
\hline 24 & Yellow & 5465 & $75.19 \times 10^{4}$ & 292.8 & 67,400 & $1952-2015$ & MWRC, 2019 \\
\hline 25 & Guangli & 47.3 & 500 & / & Silted & / & Yang et al., 2005 \\
\hline 26 & Zimai & 134.55 & 3356 & / & / & / & / \\
\hline 27 & Xiaoqinghe & 233 & $10,498.8$ & 8.78 & 36.9 & / & Chen et al., 1998 \\
\hline 28 & Mihe & 206 & 3847 & 4.30 & 84.09 & / & Chen et al., 1998 \\
\hline 29 & Bailang & 127 & 1237 & 0.39 & / & / & Yao et al., 2014 \\
\hline 30 & $\mathrm{Yu}$ & 75 & 890 & / & / & / & Yao et al., 2014 \\
\hline 31 & Wei & 242 & 6367 & 14.46 & 92.44 & / & Chen et al., 1998 \\
\hline 32 & Wang & 50 & 449.19 & / & / & / & / \\
\hline 33 & $\mathrm{Jie}$ & 45 & 576.8 & / & / & / & / \\
\hline 34 & Jia & 80 & 2295.5 & 6.15 & 34 & 1953-1957; 1966-1979 & Jin et al., 2007 \\
\hline
\end{tabular}

rivers around the Bohai Sea are investigated in this study (Table 1). Larger rivers flowing into the Bohai Sea mainly include the Yellow, Haihe, Liaohe, and Luanhe Rivers (Fig. 1). The Yellow River is the second-longest river in China, originating from the Tibetan Plateau and flowing through the Loess Plateau and North China Plain (Milliman and Meade, 1983). The annual average runoff is $292.8 \times 10^{8} \mathrm{~m}^{3}$ (MWRC, 2019) and annual mean sediment load is 674 Mt. The Haihe and Luanhe Rivers originate from the mountains on the northwest side of the North China Plain, and flow through large, heavy industry cities, Tianjin and Tangshan, respectively. The Liaohe River passes through the Northeastern China Plain. Due to the regional precipitation being controlled by the monsoon, river sediment is particularly abundant in summer and autumn. For instance, the runoff between June and September accounts for about 3/4 of the annual runoff of the Luanhe River. For the Yellow River, runoff, and sediment load from July to October accounts for $60 \%$ and $80 \%$ of the annual quantities, respectively (Su and Yuan, 2005).

Based on lithological differences in the catchment areas, the surrounding rivers can be divided into nine possible provenance groups (Fig. 1). The Dayang and Biliu rivers (Region A) originate from the Liaodong Peninsula mountains covered by Proterozoic monzonitic granite and Indosinian to Jurassic monzonitic granite, respectively (Liaoning Bureau of Geology and Mineral Resources, 1989). The Fuzhou River (Region B) in the western Liaodong Peninsula flows through Upper Proterozoic shale, sandstone, and limestone (Liaoning Bureau of Geology and Mineral Resources, 1989). The Liaohe and Daliao rivers (Region C) mainly flow through plains covered by Quaternary sediments. The Daling and Xiaoling rivers charging the western Liaodong Bay (Region D) coast flow through Jurassic and Cretaceous andesite, rhyolite, shale, and sandstone, and Archaean gneissic granite. Archaean gneissic granite is widely distributed in the west side of the Liaodong Bay. The Luanhe-Haihe River System, including the Luanhe, the Xiaoqinglong, the Dou, the Chaobai, the Yongding, the Jiyun, the
Haihe, the Dagu, the Beipai, the Duliujian, and the Ziyaxin rivers (Region E), flows through Archean metamorphic rocks (e.g., amphibolite, gneiss) and Quaternary sediment in the broad northern China plain (Hebei Bureau of Geology and Mineral Resources, 1982). These rivers pass through or close to big cities, including Beijing, Tianjin, and Tangshan (Fig. 1).

The Xuanhui, Zhangweixin, Majia, and Tuhai rivers of the Haihe River System in the southern Bohai Bay and the Yellow River system further east have the same catchment (Region F), as the these rivers were captured bv the Yellow River several times over the past thousand years (Ye, 1989a, b). Loess terrain in the middle reaches provides more than 90\% sediment to the Yellow River (Ren et al., 1986). Rivers close to the southern Laizhou Bay (Region G) pass through mountains covered by Archaean metamorphic rocks and a plain with the Quaternary sediment. Rivers in the western and northern Shandong Peninsula (Regions $\mathrm{H}$ and I) flow through granite regions (Shandong Bureau of Geology and Mineral Resources, 1991).

\subsection{Marine hydrodynamic characteristics}

Most areas of the Bohai Sea are controlled by regular, semidiurnal tides (Qiao et al., 2008). The tidal range and flow rate in most areas of the Bohai Sea are $2-3 \mathrm{~m}$ and $0.5-2.0 \mathrm{~m} / \mathrm{s}$, respectively. Waves in the Bohai Sea is mainly caused by wind, with average heights of $1.1-1.7 \mathrm{~m}$ in January, 3.5-6.0 m during cold periods, and $6 \mathrm{~m}$ during occasional typhoons. The waves have a particularly strong influence in the Bohai Strait and the central sea (Feng et al., 2007). Ocean circulations of the Bohai Sea include the Yellow Sea Warm Current, the Liaonan Coastal Current, the Liaodong Coastal Current, and the southern Bohai Sea Coastal Current (Fig. 2). Surface circulations are controlled by the regional winds with directions of the north in winter and southeast in summer (J. Wang et al., 2010b) . In winter, the high-salinity Yellow Sea 

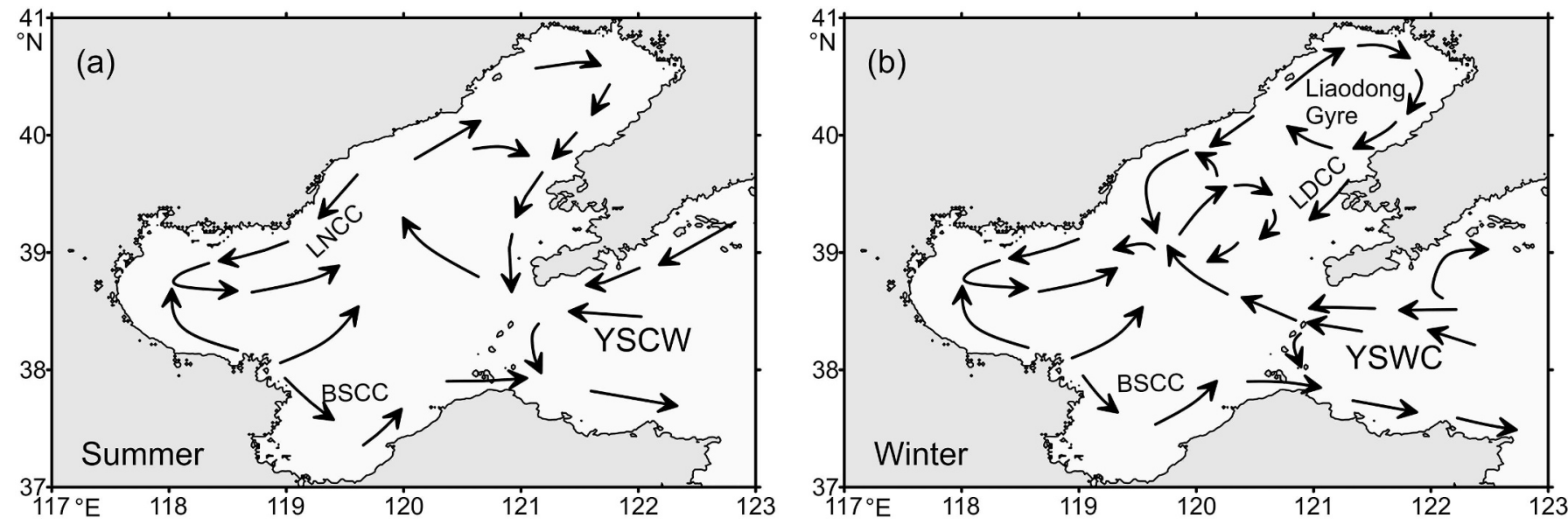

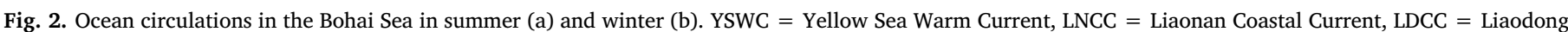

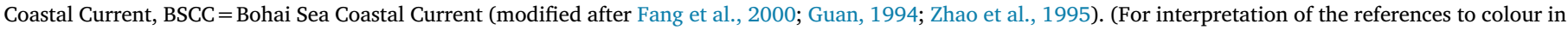
this figure legend, the reader is referred to the web version of this article.)

Warm Current enters the Bohai Sea from the Yellow Sea through the northern Bohai Strait (Fig. 2b). In the northwestern Bohai Sea, the current is divided into two branches. One branch moves northward along the west bank of the Liaodong Bay and forms the anti-cyclonic Liaodong Gyre and two weak reversed gyres (Fig. 2b; Fang et al., 2000). Another branch moves into the Bohai Bay and forms a counterclockwise circulation when encountering the diluted northward-directed Yellow River water (Zhao et al., 1995). The Yellow-River water flows via the Laizhou Bay and the southen Bohai Strait into the Yellow Sea (Guan, 1994). Strong winter winds with cold surges lead to a vertical mixture of the water body in the Bohai Sea and drives the currents southward (Su, 1998). In summer, with the weakening or disappearance of the Yellow Sea Warm Current, the cold bottom tongue from the Yellow Sea Cold Water enters the Bohai Sea through the Bohai Strait (Guan, 1994). In addition, the summer winds drive northward boundary currents in the shallow waters near the coast (Dou et al., 2014). Within the Liaodong Bay, the current moves clockwise in the long-term, but in the opposite direction when the Liaohe River discharge increases, and favourable wind prevails (Guan, 1994). Currents of the Bohai and Laizhou bays in summer resemble that in winter (Zhao et al., 1995).

\section{Materials and methods}

\subsection{Sample acquisition}

During two survey cruises in 2014 and 2016, the uppermost $10 \mathrm{~cm}$ of sediment from 167 sites in the study area was collected with a stainless grab sampler. 121 samples are from the Bohai Sea, 34 from surrounding rivers, and 12 from the north Yellow Sea (Fig. 1). There are 104 marine samples correspond to clayey silt (YT), silt (T), and sandsilt-clay (STY) (Fig. 1), according to the classification of Liu et al. (2010). Each sample was packed into a non-magnetic, $8 \mathrm{~cm}^{3}$ plastic cube and weighed after dried below $40{ }^{\circ} \mathrm{C}$.

\subsection{Magnetic parameters and measurements}

Volume low- and high-frequency magnetic susceptibility ( $\kappa_{\mathrm{lf}}$ and $\left.\kappa_{\mathrm{hf}}\right)$ were measured at low $(976 \mathrm{~Hz})$ and high frequency $(15,616 \mathrm{~Hz})$ under low fields (200 m/A) using a Kappabridge MFK1-FA (AGICO). Mass susceptibilities $\left(\chi_{\text {lf }}\right.$ and $\chi_{\mathrm{hf}}$ ) were then obtained as $\kappa_{\mathrm{lf}}$ and $\kappa_{\mathrm{hf}} \mathrm{di}$ vided with the sample density. Frequency-dependent magnetic susceptibility $\left(\chi_{\mathrm{fd}}\right)$ was calculated from $\chi_{\mathrm{fd}}=\left[\left(\chi_{\mathrm{lf}} \chi_{\mathrm{hf}}\right) / \chi_{\mathrm{lf}}\right] \times 100 \%$, and it serves as an indicator to the relative content of the ultra-fine magnetic particles close to the superparamagnetic (SP)/single domain (SD) boundary of ferrimagnetic minerals (Oldfield, 1991).
Each sample was applied to an alternating field (AF) with a peak field of $100 \mathrm{mT}$ with a direct current (DC) bias field of $0.05 \mathrm{mT}$ by a D2000 AF demagnetizer to get an anhysteretic remanent magnetization (ARM), which is regarded as a representative of the stable single-domain ferrimagnetic content (Oldfield, 1991). The ARM was measured by a JR-6A Spinner Magnetometer (AGICO). The susceptibility of anhysteretic remanent magnetization $\left(\chi_{\text {ARM }}\right.$ ) was the result of the ARM divided by the DC bias $(0.05 \mathrm{mT})$. Saturation isothermal remanent magnetization (SIRM) was imparted to the $Z$-axis for each sample at a DC field of $1 \mathrm{~T}$ using an IM-10-30 Impulse Magnetizer and was measured by the JR-6A Spinner Magnetometer (AGICO). The values of SIRM rely on the content of magnetic minerals primarily and magnetic crystal grain size secondarily, but irrelevant with superparamagnetic domains. Then each sample was put into back-fields $(-100 \mathrm{mT}$, $-300 \mathrm{mT}$ ) and the isothermal remanent magnetizations in back-fields $\left(\right.$ IRM $\left._{-100 \mathrm{mT}}, \mathrm{IRM}_{-300 \mathrm{mT}}\right)$ were measured. The S-ratio $\left(\mathrm{S}_{-300}\right)$ is often used to show the relative content of ferrimagnetic (e.g, magnetite, and maghemite) and anti- ferromagnetic mineral (e.g, hematite, and goethite) within a sample. It was calculated using the formula $\mathrm{S}_{-300}=\left(\right.$ SIRM-IRM $\left._{-300 \mathrm{mT}}\right) /(2 \times \mathrm{SIRM})$ (Bloemendal et al., 1992). High content of ferrimagnetic minerals corresponds to high $\mathrm{S}_{-300}$ value close to 1. "Hard" isothermal remanent magnetizations (HIRM) is roughly proportional to the absolute content of anti-ferromagnetic mineral (e.g., hematite and goethite) in a sample and is computed using the formula HIRM $=\left(\right.$ SIRM $_{+}$IRM $\left._{-300 \mathrm{mT}}\right) / 2$ (Bloemendal et al., 1993). The L-ratio was calculated as L-ratio $=\left(\right.$ SIRM-IRM $\left._{-300 \mathrm{mT}}\right) /($ SIRM-IRM 100mT) (Liu et al., 2007). $\chi_{\text {ARM }} /$ SIRM was used to reflect magnetic grain sizes because it is not affected by superparamagnetic grains. High $\chi_{\text {ARM }} /$ SIRM value reflects high content of single-domain grains, and low $\chi_{\text {ARM}} /$ SIRM values reflect coarse magnetic grain sizes (Bloemendal et al., 1992; Robinson, 1986). All of the measured/calculated magnetic parmaters are listed in Table 2.

\subsection{Diffuse reflectance spectroscopy measurements and calculations}

Diffuse reflectance spectroscopy (DRS) is a useful method to quantify both hematite and goethite contents (Deaton and Balsam, 1991) and has been used widely in marine sediment (Li et al., 2019; Zhang et al., 2018). DRS was measured for all samples using a Cary $5000 \mathrm{ul}-$ traviolet-visible-infrared spectrometer equipped with $\mathrm{BaSO}_{4}$ as the white standard. DSR were recorded in the spectrum range from 300 to $2,600 \mathrm{~nm}$ in $0.5-\mathrm{nm}$ steps at a scan rate of $300 \mathrm{~nm} / \mathrm{min}$. Detailed DRS methods were introduced by Zhang et al. (2018). Results are shown in forms of the band intensities for hematite and goethite ( $\mathrm{I}_{\text {hem }}$ and $\mathrm{I}_{\text {goe }}$ ), and the $\mathrm{Hem} /(\mathrm{Hem}+\mathrm{Goe})$ was calculated with the equation: Hem/ 
Table 2

Magnetic parameters referred in this paper and their meanings (after Liu et al., 2007; Maher, 2007; Oldfield, 1991; Torrent et al., 2007; Zhang et al., 2018).

\begin{tabular}{|c|c|c|}
\hline Magnetic parameter & Abbreviate & Meaning of the parameter \\
\hline Low-frequency magnetic susceptibility & $\chi_{\mathrm{lf}}$ & $\begin{array}{l}\text { Indicator of the total magnetic mineral concentration, including low-coercivity magnetic/ } \\
\text { ferrimagnetic minerals (e.g., magnetite, maghemite), high-coercivity magnetic/anti- } \\
\text { ferromagnetic minerals (e.g., hematite, goethite), with different magnetic domains } \\
\text { (superparamagnetic domain, single domain, "pseudo-single domain," and multidomain). }\end{array}$ \\
\hline Frequency-dependent magnetic susceptibility & $\chi_{\mathrm{fd}}$ & $\begin{array}{l}\text { Contribution of the ultra-fine grains (mainly the superparamagnetic grains) to the total } \\
\text { magnetic mineral concentration }\left(\chi_{1 f}\right) \text {. }\end{array}$ \\
\hline Anhysteretic remanent magnetization & ARM & Proportional to the concentration of the stable single domains. \\
\hline Saturation isothermal remanent magnetization & SIRM & $\begin{array}{l}\text { Concentration of remanence-carrying magnetic minerals, but independent with the } \\
\text { superparamagnetic grains. }\end{array}$ \\
\hline "Hard" isothermal remanent magnetization & HIRM & $\begin{array}{l}\text { Indicative of the absolute concentration of the high-coercivity magnetic minerals (e.g., } \\
\text { hematite, goethite). }\end{array}$ \\
\hline S-ratio & $\mathrm{S}_{-300}$ & $\begin{array}{l}\text { Ratio of low-coercivity minerals (e.g. magnetite, maghemite) to concentration of remanence- } \\
\text { carrying magnetic minerals (SIRM). High S-ratio (close to } 1 \text { ) indicates a high proportion of } \\
\text { low-coercivity minerals (e.g., magnetite, maghematite), while low S-ratio (close to 0) indicates } \\
\text { a high proportion of high-coercivity minerals (e.g., hematite, goethite). }\end{array}$ \\
\hline L-ratio & L-ratio & $\begin{array}{l}\text { Judge the availability of HIRM. Changes in HIRM only reflect changes in the absolute } \\
\text { concentration of hematite and/or goethite if the L-ratio is relatively constant. }\end{array}$ \\
\hline $\begin{array}{l}\text { Ratio of anhysteretic remanent magnetization to } \\
\text { saturation isothermal remanent magnetization }\end{array}$ & $\chi_{\text {ARM }} /$ SIRM & $\begin{array}{l}\text { Indicator of grain size of magnetic mineral crystal. High } \chi_{\text {ARM }} / \text { SIRM value suggests a high } \\
\text { content of SSD grains. }\end{array}$ \\
\hline Band intensity of goethite & $I_{\text {goe }}$ & Proportional to the concentration of goethite. \\
\hline Band intensity of hematite & $\mathrm{I}_{\text {hem }}$ & Proportional to the concentration of hematite. \\
\hline Ratio of hematite to goethite and hematite & $\mathrm{Hem} /(\mathrm{Goe}+\mathrm{Hem})$ & Ratio of hematite concentration to the total concentration of goethite and hematite. \\
\hline
\end{tabular}

$(\mathrm{Hem}+\mathrm{Goe})=-0.133+2.871 \mathrm{X}-1.709 \mathrm{X}^{2}$, where $\mathrm{X}$ is the $\mathrm{I}_{\mathrm{hem}} /$ ( $\mathrm{I}_{\text {hem }}+\mathrm{I}_{\text {goe }}$ ) (Torrent et al., 2007).

All of the above-mentioned measurements in this study were completed at the Institute of Geology and Geophysics, Chinese Academy of Sciences (Beijing, China).

\subsection{XRD and SEM-EDS analyses for extracted magnetic minerals}

Morphology and composition analysis were performed for representative extracted magnetic minerals. Magnetic extraction was performed for ten dired samples, including 6 river and 4 marine samples, using a magnet housed in a glass sheath. All of the extracted samples were performed with X-ray diffraction (XRD) analysis with a Xray diffractometer (Bruker D8 Advance). The X-ray scans were run from $5^{\circ}$ to $90^{\circ}(2 \theta)$. Results are presented after subtraction of the background trend. Seven of the extrated samples, including 6 river samples and 1 marine sample, were observed by the scanning electron microscope with energy dispersive spectrometer (SEM-EDS). Observations of magnetic extracts were made using a Quanta FEG 250 Field-emission SEM with the magnification of $1500 \times-6000 \times$ and an acceleration voltage of $20 \mathrm{kA}$. Chemical spectra of minerals were obtained using an Oxford Instruments Ltd. INCA X-MAX-50 EDS. Two particles in every sample were photographed, and were scanned with chemical spectra.

\section{Results}

\subsection{Magnetic properties for river sediments}

Region D (the Daling and Xiaoling rivers) has the highest magnetic concentration with $\chi_{\text {lf }}$ values higher than $160 \times 10^{-8} \mathrm{~m}^{3} / \mathrm{kg}$, followed by Regions E, A, and I with $\chi_{1 \mathrm{f}}$ values around $80 \times 10^{-8} \mathrm{~m}^{3} / \mathrm{kg}$ (Fig. 3a, Table S1). Regions B and C on the northeast, and Regions F and $\mathrm{G}$ on the southwest have the similar $\chi_{\mathrm{lf}}$ values of $20-60 \times 10^{-8} \mathrm{~m}^{3} / \mathrm{kg}$. Magneic mineral concentrations of the two rivers in Region $\mathrm{H}$ are changeable, with $\chi_{\text {lf }}$ values of 10 and $40 \times 10^{-8} \mathrm{~m}^{3} / \mathrm{kg}$. The orders of SIRM and ARM in provenance regions resemble to $\chi_{1 \mathrm{lf}}$, with some discrepancies in Regions A, E and I (Fig. 3a-c).

$\chi_{\mathrm{fd}}$ values are higher than $4 \%$ for most river samples, except samples in Region D (Fig. 3d). Samples in Regions A, C, E, F, and G have the similar $\chi_{\mathrm{fd}}$ values ranging from approximately $4 \%$ to $10 \%$. Most sediments in Regions B and H contain higher $\chi_{\mathrm{fd}}$ values than other regions.

HIRM values in Regions A and I are lower than most samples, except the two samples with negative values in Regions D and G. In total, HIRM values of Regions B, C, D, and E in the north are higher than Regions F, G, H, I in the south (Fig. 3e).

$S_{-300}$ values are higher than 0.90 for all samples (Fig. $3 f$ ). The high $\mathrm{S}_{-300}$ values occur in Region A, D, and I, and the low values occur in Regions B, F, and H. Rivers in Region $\mathrm{G}$ have evidently changeable $\mathrm{S}_{-300}$ values. L-ratio values are mainly concentrated in $0.2-0.4$, despite the presence of outliers (Fig. $3 \mathrm{~g}$ ). $\chi_{\text {ARM }} / \mathrm{SIRM}$ values for $80 \%$ samples are less than $30 \times 10^{-5} \mathrm{~m} / \mathrm{A}$. Sediments in Region B and part of Regon E contain the high $\chi_{\text {ARM }} /$ SIRM values (Fig. 3 h).

$\mathrm{I}_{\text {goe }}$ values are changeable in Regions A-C of the Liaodong Peninsula, and increase from Regions D and E on the northwest to Regions F, G, H, I on the south (Fig. $3 \mathrm{i}$ ). $\mathrm{I}_{\mathrm{hem}}$ values are lower than $12 \times 10^{-5}$ for all samples except some samples from Region $\mathrm{H}$ (Fig. 3j). $\mathrm{I}_{\text {hem }}$ values for samples in Regions A-C are changeable, while the $\mathrm{I}_{\text {hem }}$ values for samples in Regions D-G are restricted in 4-12 $\times 10^{-5}$. Hem/ (Goe + Hem) are low in Regions A-B and I, high in Regions $\mathrm{C}-\mathrm{F}$ and $\mathrm{H}$, and moderate in Region G (Fig. 3k).

\subsection{Magnetic properties for the Bohai and North Yellow seas}

Values of $\chi_{\text {lf }}$ and SIRM are high in the western coast of Bohai Sea, especially the northern Bohai and western Liaodong bays, and decrease southeastward (Fig. 4a, b). $\chi_{\text {lf }}$ and SIRM are correlated to a large extent (Fig. 5b). $\chi_{\text {If }}$ and ARM are more correlated with low values than high values (Fig. 5c). ARM presents high values in the the mud area of central Bohai Bay to northern Liaodong Bay, similar to the distribution of $\chi_{\text {ARM }} /$ SIRM. $\chi_{\mathrm{fd}}$ present high values not only in the mud area, but also the areas close to the estuaries in the southern Bohai Bay and eastern Liaodong Bay.

HIRM is uncorrelated to L-ratio for most samples from the Bohai and north Yellow seas except three abnormal samples from the Laizhou Bay (Fig. 5a), which implies the HIRM is useful to reflect the anti-ferromagnetic (e.g., hematite and goethite) mineral content in the sea (Liu et al., 2007). HIRM resemble to $\chi_{\mathrm{fd}}$ in the Laizhou and Bohai bays, rather than the Liaodong Bay and the central sea. HIRM presents high values in the west Liaodong Bay, and decreases eastward, consistent with $\chi_{\text {lf }}$ and SIRM (Fig. 4).

$\mathrm{S}_{-300}$ is higher than 0.86 for all marine sediment samples. $\mathrm{S}_{-300}$ values of sediment from the northern Bohai Sea are higher than those of sediments from the southern sea (Table S1). L-ratio is the highest in northeastern Laizhou Bay, the central Bohai Bay, and the central sea. 

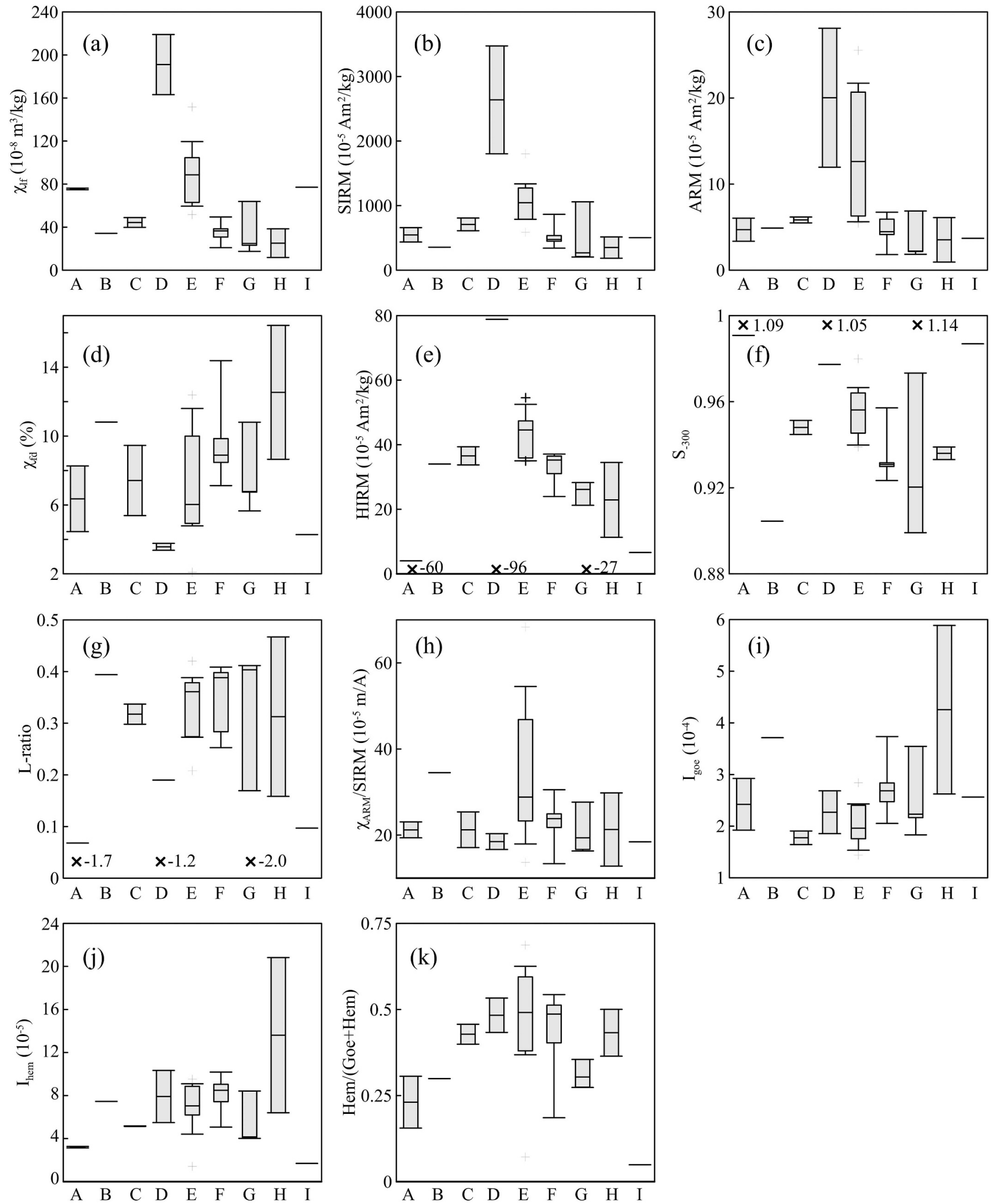

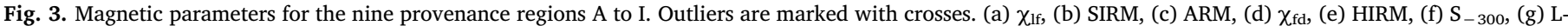
ratio, (h) $\chi_{\text {lf }} / S I R M,(i) I_{\text {goe }},(j) I_{h e m}$, and (k) Hem/(Goe + Hem). 

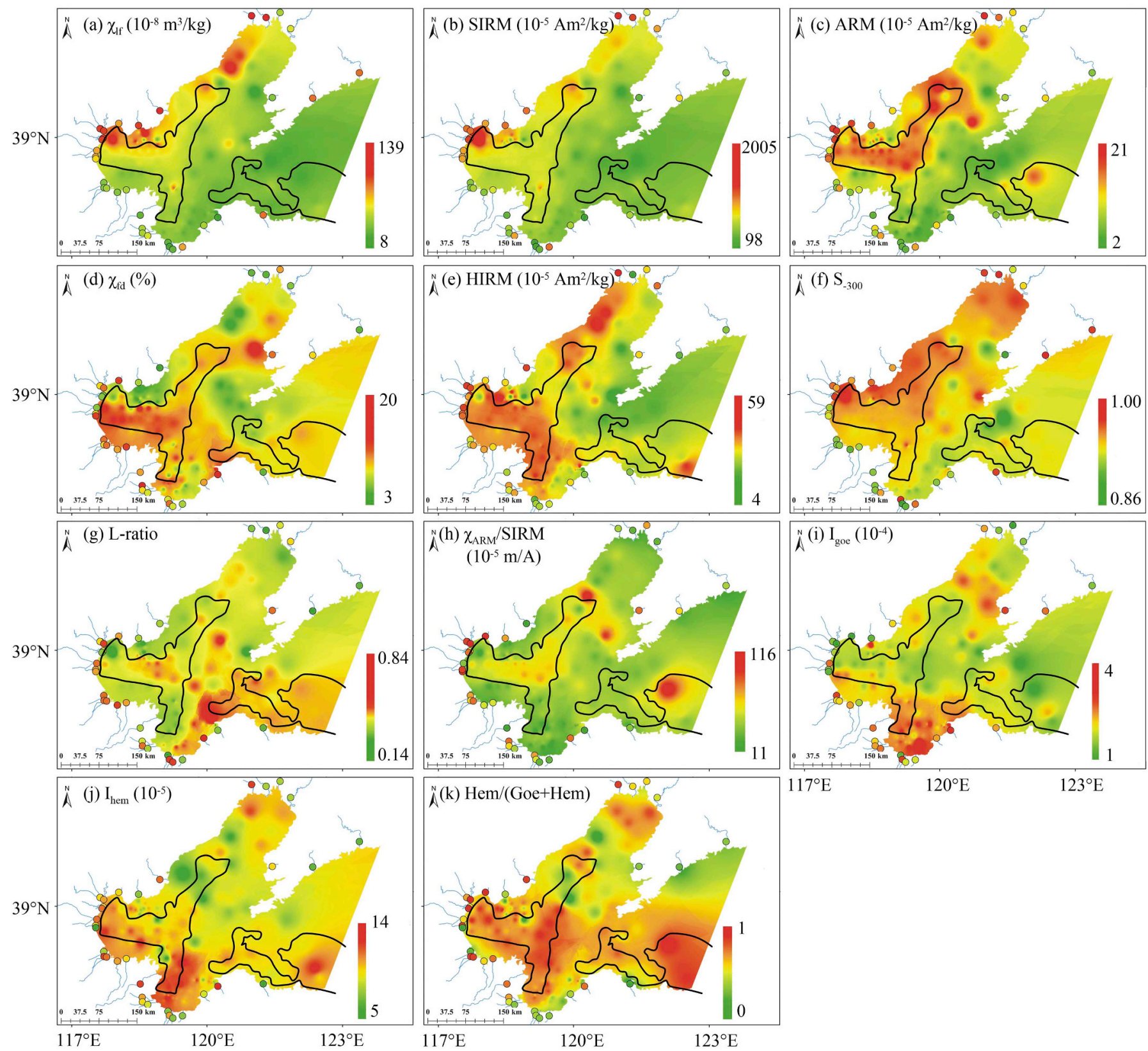

$117^{\circ} \mathrm{E}$

$120^{\circ} \mathrm{E}$

$123^{\circ} \mathrm{E}$

$117^{\circ} \mathrm{E} \quad 120^{\circ} \mathrm{E} \quad 123^{\circ} \mathrm{E}$

$117^{\circ} \mathrm{E}$

$120^{\circ} \mathrm{E}$

$123^{\circ} \mathrm{E}$

Fig. 4. Spatial distributions of magnetic properties, including (a) $\chi_{\text {If }}$, (b) SIRM, (c) ARM, (d) $\chi_{\mathrm{fd}}$, (e) HIRM, (f) $S_{-300}$, (g) L-ratio, (h) $\chi_{\text {ARM }} / S_{\text {IRM, }}$ (i) $I_{\text {goe }}$, (j) $I_{\text {hem }}$, and (k) Hem $/($ Goe + Hem). Solid dots show values for the surrounding rivers. The two mud areas (defined by Mz more than $6 \varphi$ ) were delineated by black lines $(Q i a o$ et al., 2017).

$I_{\text {goe }}$ is the highest in the Laizhou Bay, especially in the southern and northeastern bay. Similar to HIRM, particularly high $\mathrm{I}_{\text {hem }}$ values are presented in the Laizhou and Bohai bays. Hem/(Goe + Hem) is similar to HIRM and $\mathrm{I}_{\text {hem }}$ in most regions except Liaodong Bay.

In the north Yellow Sea, values of ARM, HIRM, L-ratio, $\chi_{\text {ARM }} /$ SIRM, $I_{\text {goe }}, I_{\text {hem }}$, and Hem/(Goe + Hem $)$ are higher in the south than the northern areas. Other magnetic parameters are slightly changed in spatial.

\subsection{Major features of magnetic minerals from the XRD and SEM-EDS}

The extracted samples are mainly consist of magnetite, hematite, and goethite, with the mix of quartz (Fig. 6c, f, i). Magnetic particles present octahedral structure, subangular shape with numerous dissolution pits, and spherical structure (Figs. 6a, d, g, S1). Grain sizes of all observed magnetic particles are nearly 20-70 $\mu \mathrm{m}$ (Fig. S1). Spherical magnetie particles, which are thought to be from human activities, were found in Rivers 04, 06, 14, 24, and 27 (Fig. S1). In contrast, the octahedral and subangular magnetic minerals are the typical detrital minerals with natural origins that are respectively unground and ground during transport processes (Badesab et al., 2018; Horng and Huh, 2011). In total, magnetic particles of the Daling and Luanhe rivers (Nos. 06 and 08), west coast of the Bohai Sea are coarser than other areas. The $70 \mu \mathrm{m}$-size magneties, the largest of all observed magnetic minerals, were detected in the Luanhe River and its adjacent sea area (Particle 2 of CFD 38, Fig. S1). The scanned minerals are mainly consist of $\mathrm{Fe}, \mathrm{O}, \mathrm{Si}, \mathrm{Al}$, and $\mathrm{Ti}$, which are indicatives of the magnetite/titanomagnetite (Fig. S1). The Ti-contents are changebale in titanomagnetite (Fig. S1), so for simplicity, we prefer to use magnetite in the following discussion. 

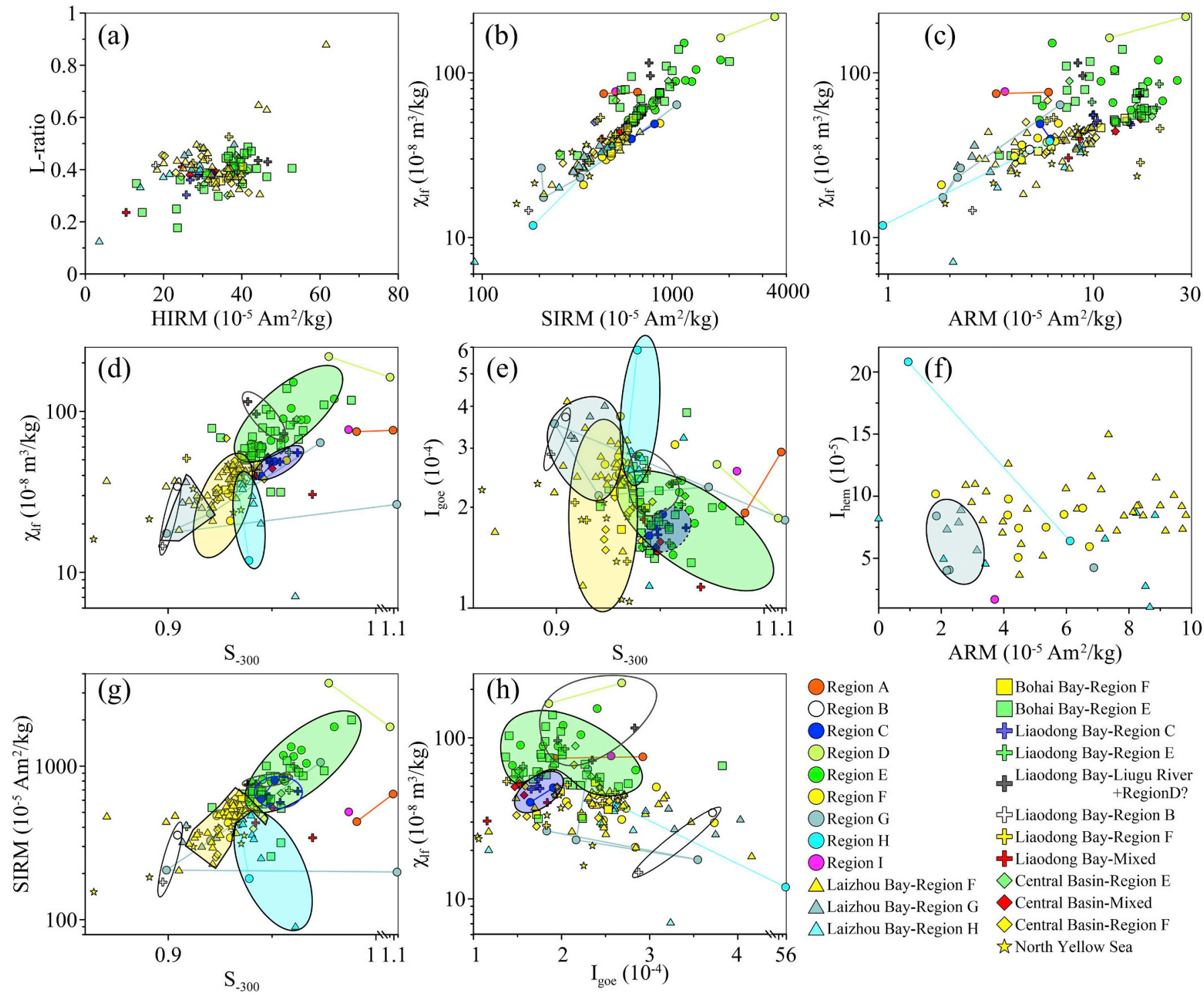

Fig. 5. Scatter plots of (a) HIRM and L-ratio, (b) $\chi_{\text {lf }}$ and SIRM, (c) $\chi_{\text {If }}$ and ARM, (d) $\chi_{\text {If }}$ and $S_{-300}$, (e) $I_{g o e}$ and $S_{-300}$, (f) $I_{\text {hem }}$ and ARM, (g) SIRM and $S_{-300}$, and (h) $\chi_{\text {If }}$ and $\mathrm{I}_{\mathrm{goe}}$. Possible provenances are delineated.

\section{Discussion}

\subsection{Controlling factors on the magnetic properties in the source regions}

Parent rock plays a significant role in magnetic minerals of source regions, especially for Regions C, E, and F, the most important sediment contributors. The concentration of magnetic minerals for river sediments in Region $\mathrm{E}$ is higher than Regions $\mathrm{C}$ and $\mathrm{F}$, probably because some metamorphic rocks in Region $\mathrm{E}$ have extremely strong magnetism. For instance, the SIRM values of amphibolite in Region $\mathrm{E}$ are higher than $10 \mathrm{Am}^{2} / \mathrm{kg}$ (Piper and Zhang, 1999), over a thousand times larger than the Bohai Sea sediments (Fig. 4b). The parent rocks of Region E must result in the enrichment of magnetic minerals in rivers, because the number of magnetite particles in the sediments of Luanhe River, Region $\mathrm{E}$ was several ten times higher than the sediments of Yellow River, Region F (Chen et al., 1980; Wang et al., 2013). Magnetic minerals in Region F contain more SP particles, and hematite and goethite than Regions C and E (Li et al., 2012; Zhang et al., 2008), which are consistent with the primary source region of the Yellow River, the loess in the river's middle reaches (Maher, 2007). In Region C, the magnetic minerals are mainly derived from the downstream Quarternary sediments, with the addition of weathered granite and quartz sandstone from the upstream. The substance mixture results in the medium magnetic mineral concentration and $\mathrm{S}_{-300}$ and coarse magnetic particles (Fig. 3).

The very high contents of SP particles and goethite in the Regions B and $\mathrm{H}$ are probably due to the strong pedogenesis that produces the formations of SP particles and goethite (Torrent et al., 2007). The main covered soils in Regions B and $\mathrm{H}$ are alfisols, different to semi-alfisols and semi-hydromorphic soils in other regions (Shi et al., 2004). Higher content of goethite in Regions B and $\mathrm{H}$ than other regions can be formed due to the evident eluviation, as iron is released from soild $\mathrm{Fe}^{\mathrm{II}}$ compounds such as $\mathrm{Fe}$ silicates in the parent materials, i.e. granite and sedimentary, and is finally oxidized in an aerobic environment (Cornell and Schwertmann, 2003).

The influences of human activities on magnetic minerals in source regions are evident, due to the ubiquitous spherical magnetie particles within the river samples (Fig. 6a, S1). Especially, magnetic minerals in Region D are mainly from human activies, because the magnetic properties, i.e. very high coarse magnetic mineral concentration with low contents of SP particles and hematite and goethite, seem to be irrelevant to weathering and pedogenesis. The very high content of 


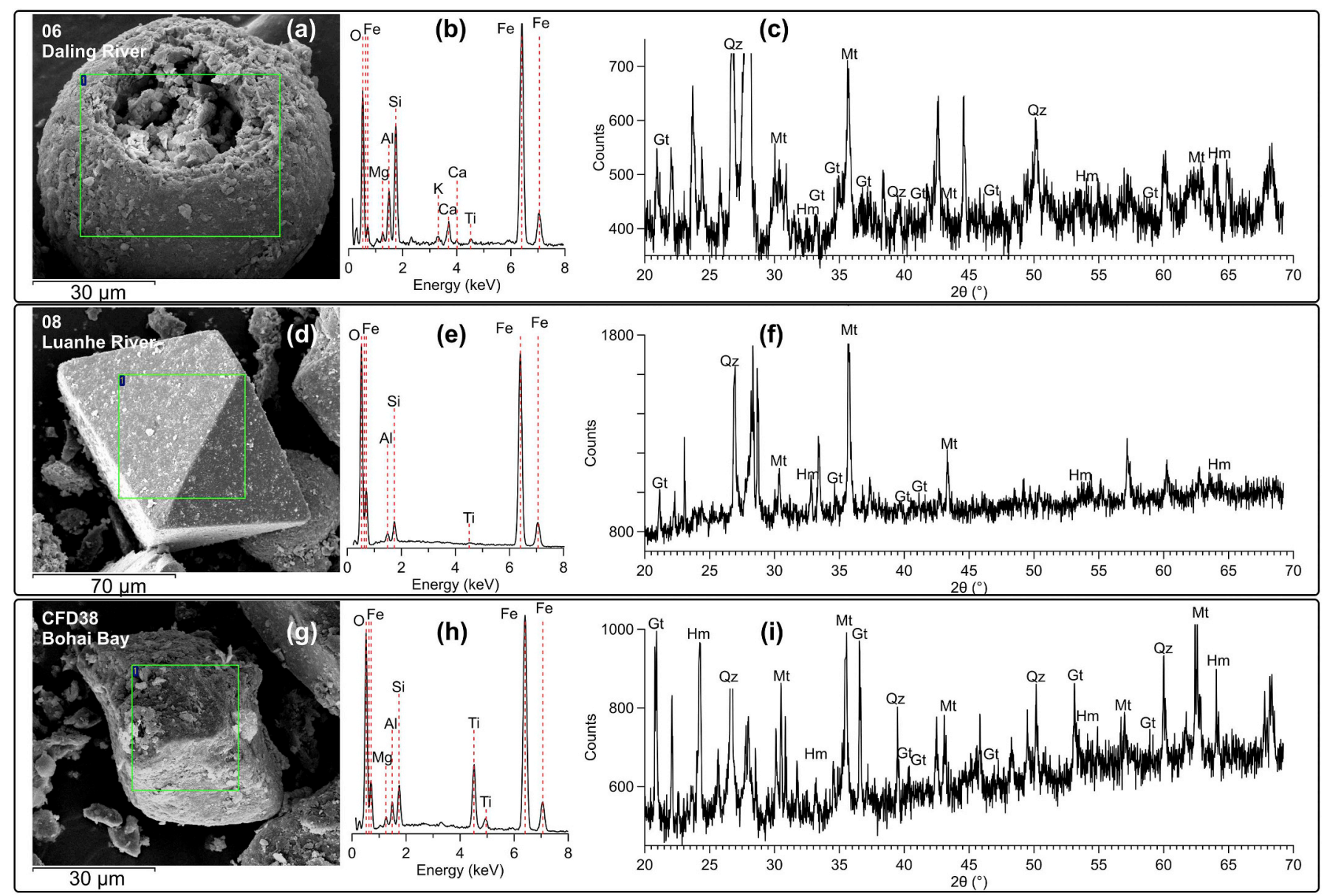

Fig. 6. SEM images (a, d, g), EDS (b, e, h), and XRD (c, f, i) of magnetic extracts from surface sediments of Rivers 06 (Daling River) and 08 (Luanhe River), and the Bohai Bay. In the XRD plots, Mt. = magnetite, Gt = goethite, $\mathrm{Hm}=$ hematite, and Qz = quartz. Note that, magnetite in the Luanhe River is coarser than other areas.

nearly pure magnetite tends to present in the anthropogenic magnetic minerals, e.g., fly ashes from factories (Jordanova et al., 2004; Veneva et al., 2004; Zhang et al., 2011). The two rivers in Region D flow through Jinzhou (Fig. 1), an industrial city with petroleum processing, ferrous metal smelting, and coking, which probably provides non-negligible anthropogenic magnetic minerals to the rivers.

The possible reductive diagenesis after deposition should be particularly concerned, because once it occurs, the primary iron oxides would be reduced into iron sulfides, including greigite and pyrite (Roberts et al., 1999). The post-depositional influence on magnetic minerals in the source regions and Bohai Sea could be rule out, because the iron sulfides were not found in the XRD and SEM results. The greigite can be identified by sensitive magnetic changes such as the increased SIRM/ $\chi_{\text {If }}$ value (Abrajevitch and Kodama, 2011; Ge et al., 2017; Roberts, 1995). The SIRM/ $\chi_{\text {If }}$ value lower than $20 \mathrm{kA} / \mathrm{m}$ for all samples closes to the iron oxides (Maher, 2007; Roberts, 1995). This is consistent with previous studies, which demonstrated that terrigenous iron hydroxides/oxides (magnetite, hematite, and goethite) predominate the Bohai Sea surface sediments (Wang et al., 2015; Y. Wang et al., 2010; Wang et al., 2017).

\subsection{Sources and pathways of magnetic minerals}

The correlations between magnetic-concentration parameters, including $\chi_{1 \mathrm{ff}}$ and SIRM, and $\mathrm{S}_{-300}$ (Fig. $5 \mathrm{~d}, \mathrm{~g}$ ) indiacte that sediments from Region $\mathrm{F}$ are transported to most regions of the Laizhou Bay, southern Bohai Bay, and the central Bohai Sea, and can be carried away to the Liaodong Bay and Yellow Sea (Figs. 5, 7). Materials in the Region $E$ with high values of $\chi_{\text {If }}$ SIRM and $S_{-300}$ were supplied to the northern
Bohai Bay, and were transported northeastward (Fig. 5d, g). Materials from Region $C$ tend to be settled along the eastern Liaodong Bay. Other local rivers, including the Fuzhou River (Region B) and rivers in Region $\mathrm{G}$ and $\mathrm{H}$, only supply sediments to the coastal waters (Figs. 5, 7). No contribution from Regions A and I can be confirmed from the magnetic data (Fig. 5).

\subsubsection{Laizhou Bay}

It can be inferred from the scatter plots of magnetic parameters that most areas of the Laizhou Bay are supplied by Region F (Figs. 5d-h, 7). High contents of fine-grained magnetic particles concentrated in the mud areas are probably due to the input and transport of suspended matters from the most sediment-filled river on Earth, the Yellow River in Region F (Qin et al., 1985; Li et al., 2010). Due to the Bohai Sea Coastal Current with three directions (Fig. 2), the Yellow River sediments tend to be transported southward, eastward and northward ( $\mathrm{Li}$ et al., 2010; Qiao et al., 2010). As a result, fine magnetic minerals are transported with the suspended matters.

Four samples in the southern Laizhou Bay seem like differ to the Region F, because they have lower magnetic mineral contents and

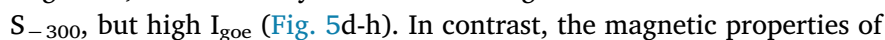
the four samples resemble to some rivers of Region G. This implies Regions G also supplies the Laizhou Bay, which is consistent with previous studies based on heavy mineralogy (K. Wang et al., 2010c). The northward residual current in the Laizhou Bay probably results in the sediment transport from Region $\mathrm{G}$ to the bay, according to previous study of numerical simulation (Li et al., 2010) (Fig. 7).

For eight samples in northeastern bay, $\chi_{\text {If }}$ and SIRM are negative correlated to $S_{-300}$ (Fig. $5 d, g$ ), in contrast to Region F. Instead, the 


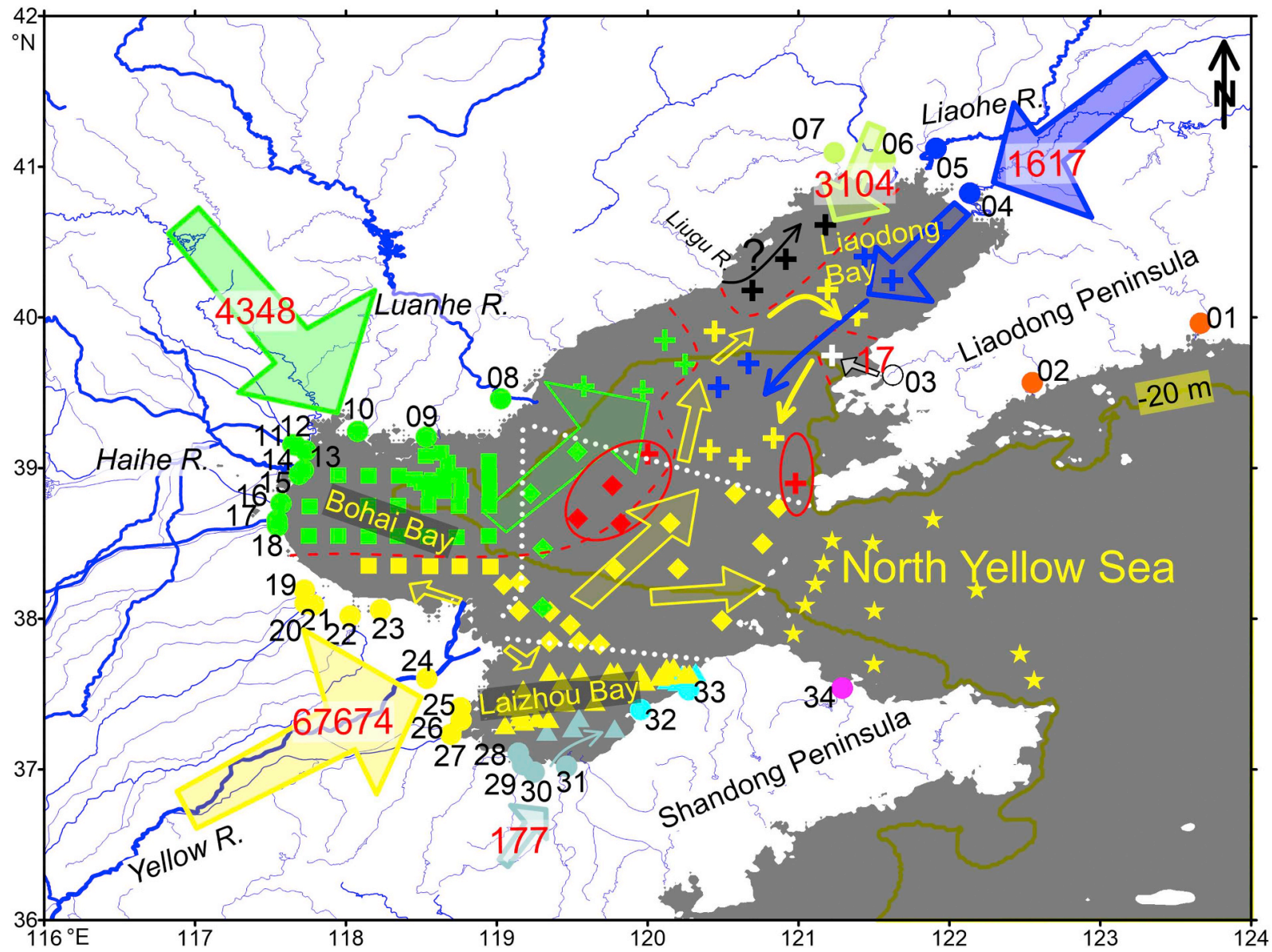

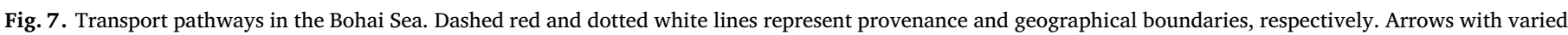

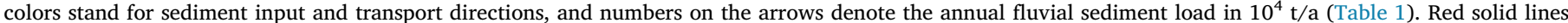

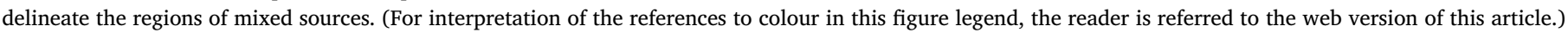

relation of magnetic parameters is close to Region H (Fig. 5d, g), which implies Region $\mathrm{H}$ is a main provenance for the region. This is consistent with previous mineralogical study (K. Wang et al., 2010c).

\subsubsection{Bohai Bay}

Most areas of the Bohai Bay except the the southern bay is supplied by Region E, according to the comparsions of magnetic parameters (Fig. 5d-h). The formation of coarse magnetie-enriched zone with medium to fine sand (MFS) in the southern Bohai Bay to western Liaodong Bay (Figs. 1, 3) is mainly ascribed to the input of the mountain rivers in Region E. Because the mountain rivers have strong water flow to carry coarse materials to the coastal area (Chen et al., 1980). The water current can hardly move away the sand-size magnetic minerals in the area. The enrichment of magnetic minerals in the western Bohai Bay close to Tianjin and Tangshan Cities is partly due to the human activities, as the spherical magnetie particles were found in River 14 (Haihe River) (Fig. S1). The magnetic minerals tend to be spreaded eastward due to the favourable currents (Fig. 2).

Sediments in the southern Bohai Bay are mainly contributed by the Region F, which can be derived from the magnetic proximity (Figs. 5, 7). The transport pathway is supported by the westward current along the coast in the northern bay (Fig. 2).

\subsubsection{Liaodong Bay}

It can be speculated from Fig. 5 that materials in the northern and partly central Liaodong Bay mainly originate from Region C. This is consitent with previous studies of mineralogy anlysis (Dou et al., 2014; Wang et al., 2014). Materials in the river estuaries of Region C are transported southward by the Liaodong Gyre and Liaodong Coastal Current (Fig. 2b).

Materials from Region F enter into the southeastern bay, and some areas of the central bay (Figs. 5, 7). Wang et al. (2015) also argued that the Yellow River in Region F is probably an important source of Liaodong Bay, due to the magnetic similarity between the Liaodong Bay and the Yellow River Delta. The viewpoint is not supported by the study of detrital minerals (Wang et al., 2014), because the detrital minerals were only analyzed for sand fraction that probbaly derived from the relict continental shelf. In contrast, the study of clay mineralogy support our viewpoint (Dou et al., 2014), which implies materials from Region F are likely transported to Liaodong Bay in the form of suspended matters under the favourable currents (Fig. 2; Qin et al., 1985).

$\chi_{\text {lf }}$ is negative to $S_{-300}$ for three samples in the northwestern bay, different to the Region E-derived samples (Fig. 5d), although the three samples are close to Region $\mathrm{E}$ in other scatter plots (Fig. 5e, g). Hou et al. (2017) argued that the region is supplied by Liugu River and the rivers in Region D, based on mineralogical analysis for the same three samples. However, in present study, the lack of samples from Liugu River limits our understanding on the contribution from the important river. The magnetite content of Liugu River is 3 times higher than the Luanhe River in Region E, and about 2 times higher than rivers in Region D (Wang et al., 2013). Hematite contents in the Liugu River and Region D are 2-6 times higher than Luanhe River (Wang et al., 2013). The enrichment zone of magnetic minerals in western Liaodong Bay is hardly affected by Region E, as the transport capability of the coarse magnetic minerals in Region E is limited. Therefore, the Liugu River and rivers in Region D are the possible source (Dou et al., 2014; Hou 
et al., 2017; Wang et al., 2014).

The southeastern bay is supplied by local rivers except the Yellow River. Magnetic properties of the Fuzhou River (River 03) in Region B and its adjacent sample are smiliar, and are evidently different with other sources (Fig. 5d-e, g-h; Fig. 7). This implies the possible contribution from the small river with a limited transport distance. The sample in the southeastern bay close to Laotieshan Wateway has high $S_{-300}$ and low $\chi_{\text {If }}$ and SIRM (red cross in Fig. 5), which is quite different with the surrounding rivers. The sample is classified into a mixture of different sources from the Laotieshan Wateway and the adjacent rivers, as the oscillating tide currents control the sedimentary processes (Liu et al., 1998).

\subsubsection{Central Bohai Sea and North Yellow Sea}

Based on magnetic comparsions, we infer the Central Bohai Sea is mainly supplemented from the Yellow River in Region F (Figs. 5, 7). The Yellow River-derived particles were suspended northward by the residual current and were blocked by the Yellow Sea Warm Current (Fig. 2). Region E provides materials in the northeastern region, according to the similarity of magnetic properties (Figs. 5, 7). There is a mixed region of the two provenances, with indistinguishable magnetic properties (red points in Fig. 5). The mixture of provenances is probably ascribed to the interaction effect of several currents (Fig. 2).

Magnetic properties of the North Yellow Sea sediment are close to the Yellow River System (Region F), rather than the coastal rivers (Regions A and I) (Fig. 5). This implies the north Yellow Sea is mainly supplied by the Yellow River, which is consistent with magnetic study by Wang et al., 2017 that focused on the whole Yellow Sea. The transport process is probably controlled by the southern Bohai Sea Coastal Current, which are supported by Qiao et al. (2017).

\section{Conclusions}

Surface sediments collected from the Bohai Sea and adjacent rivers were studied to reveal key information about sediment province of the sea. Magnetite, hematite, and goethite are the main magnetic minerls in the studied area, with variable concentrations and grain sizes. Magnetic properties in the river sediments are mainly affected by the combined factors of parent rocks, pedogenesis, and human activities. The integrative effect of the three factors results in the magnetic difference in the source regions, making it possible to track provanance in the sea with the magnetic methods. Based on scatter plots of magnetic parameters, such as $\chi_{\mathrm{lf}}$ and $\mathrm{S}_{-300}$, the sediment provinces corresponding to different sources were divided. The sea is supplied by both the huge rivers, e.g., the Yellow River, and local small rivers, e.g., Fuzhou River, which are due to the transport of currents. Magnetic properties of the north Yellow Sea is close to the Yellow River, which indicates a transport pathway that the Yellow River-derived sediments are suspended out of the Bohai Sea. This research is helpful to understand the provenance and transport process in the sea using the sensitive, rapid magnetic methods, and provides reference for the further study of provenance in seas.

Supplementary data to this article can be found online at https:// doi.org/10.1016/j.margeo.2020.106226.

\section{Declaration of Competing Interest}

The authors declare that they have no known competing financial interests or personal relationships that could have appeared to influence the work reported in this paper.

\section{Acknowledgments}

We are grateful to all of our colleagues on the ship for collecting the sediment samples. We are grateful to Drs. Firoz Badesab and Carita
Augustsson and Prof. Qingsong Liu for constructive comments. This work was supported by the Natural Science Foundation of Guangdong Province, China (Grant No. 2018B030311056), by the National Natural Science Foundation of China (Grant No. 41272384, 41773138 and U1806207), by the key project of Chinese Academy of Sciences (XDA11020402) and by the Postdoctoral Research Foundation of China (Grant No. 2019M652936).

\section{References}

Abrajevitch, A., Kodama, K., 2011. Diagenetic sensitivity of paleoenvironmental proxies: A rock magnetic study of Australian continental margin sediments. Geochem. Geophys. Geosyst. 12, Q05Z24.

Badesab, F.K., Gaikwad, V., Gireeshkumar, T.R., Naikgaonkar, O., Deenadayalan, K., Samiksha, S.V., Kumar, P.K.D., Loveson, V.J., Iyer, S.D., Khan, A., Udayakrishnan, P.B., Sardar, A., 2018. Magnetic tracing of sediment dynamics of mudbanks off southwest coast of India. Environ. Earth Sci. 77, 625.

Bloemendal, J., King, J.W., Hall, F.R., Doh, S.J., 1992. Rock magnetism of Late Neogene and Pleistocene deep-sea sediments: Relationship to sediment source, diagenetic processes, and sediment lithology. J. Geophys. Res. 97, 4361-4375.

Bloemendal, J., King, J.W., Hunt, A., Demenocal, P.B., Hayashida, A., 1993. Origin of the sedimentary magnetic record at ocean drilling program sites on the Owen ridge, western Arabian Sea. J. Geophys. Res. 98, 4199-4219.

Caitcheon, G.G., 1993. Sediment source tracing using environmental magnetism: a new approach with examples from Australia. Hydrol. Process. 7, 349-358.

Chen, L., Luan, Z., Zhen, T., Xu, W., Dong, T., 1980. Mineral assemblages and their distribution patterns in the sediments of the Gulf of Bohai Sea. Chin. J. Oceanol. Limnol. 1, 82-103 (in Chinese with English Abstract).

Chen, Z., Wu, S., Xia, D., Xie, Q., Chen, F., Hu, H., Zhan, J., He, B., 1998. The Bay Chorography in China, 14. Ocean Press, Beijing (in Chinese), pp. 1-799.

Cornell, R.M., Schwertmann, U., 2003. The Iron Oxides: Structure, Properties, Reactions, Occurences and Uses. Wiley-VCH, Weinheim, pp. 1-664.

Deaton, B.C., Balsam, W.L., 1991. Visible spectroscopy-a rapid method for determining hematite and goethite concentration in geological materials. J. Sediment. Res. 61, 628-632.

Dou, Y., Li, J., Zhao, J., Wei, H., Yang, S., Bai, F., Zhang, D., Ding, X., Wang, L., 2014. Clay mineral distributions in surface sediments of the Liaodong Bay, Bohai Sea and surrounding river sediments: sources and transport patterns. Cont. Shelf Res. 73, 72-82.

Ellwood, B.B., Balsam, W.L., Roberts, H.H., 2006. Gulf of Mexico sediment sources and sediment transport trends from magnetic susceptibility measurements of surface samples. Mar. Geol. 230, 237-248.

Fang, Y., Fang, G.-H., Zhang, Q.-H., 2000. Numerical simulation and dynamic study of the wintertime circulation of the Bohai Sea. Chin. J. Oceanol. Limnol. 18, 1-9.

Feng, S., Zhang, J., Wei, H., 2007. An Introduction to Environmental Dynamics of the Bohai Sea. Science Press, Beijing, pp. 1-281 (in Chinese).

Gamboa, A., Montero-Serrano, J.C., St-Onge, G., Rochon, A., Desiage, P.A., 2017. Mineralogical, geochemical, and magnetic signatures of surface sediments from the Canadian Beaufort Shelf and Amundsen Gulf (Canadian Arctic). Geochem. Geophys. Geosyst. 18, 488-512.

Ge, C., Zhang, W., Dong, C., Wang, F., Feng, H., Qu, J., Yu, L., 2017. Tracing sediment erosion in the Yangtze River subaqueous delta using magnetic methods. J. Geophys. Res.-Earth Surface 122, 2064-2078.

Guan, B., 1994. Patterns and Structures of the Currents in Bohai, Huanghai and East China Seas. In: Hu, D., Zhou, D., Liang, Y., Tseng, C.K. (Eds.), Oceanology of China Seas. Kluwer Academic Publishers, Dordrecht, pp. 17-26.

Han, Z.-Z., Yi, H.-W., Li, M., Zhang, J.-Q., Zou, H., 2013. Analysis for heavy mineral characteristics and material provenance in the sediments of the Northern Bohai Bay. Periodical of Ocean University of China 216, 73-79 (in Chinese with English Abstract).

Hatfield, R.G., Stoner, J.S., Carlson, A.E., Reyes, A.V., Housen, B.A., 2013. Source as controlling factor on the quality and interpretation of sediment magnetic records from the northern North Atlantic. Earth Planet. Sci. Lett. 368, 69-77.

Hebei Bureau of Geology and Mineral Resources, 1982. Regional Geology of Heibei Province, Beijing City and Tianjin City. Geological Publishing House, Beijing, pp. 1-741 (in Chinese with English Abstract).

Horng, C.-S., Huh, C.-A., 2011. Magnetic properties as tracers for source-to-sink dispersal of sediments: a case study in the Taiwan Strait. Earth Planet. Sci. Lett. 309, 141-152.

Hou, M., Yi, H., Sun, Z., Gao, M., Wang, X., 2017. Detrital mineral composition features of the northern Bohai Sea. Journal of Arid Land Resources and Environment 31, 118-123 (in Chinese with English Abstract).

Imai, I., Yamaguchi, M., Hori, Y., 2006. Eutrophication and occurrences of harmful algal blooms in the Seto Inland Sea, Japan. Plankton Benthos Research 1, 71-84.

Jin, B.-F., Song, J., Zhang, L., 2007. Geomorphic response to the environmental change at the mouth of the Jiahe River in Yantai since the last four decades. Mar. Sci. 31, 26-29 (in Chinese with English Abstract).

Jordanova, D., Hoffmann, V., Fehr, K.T., 2004. Mineral magnetic characterization of anthropogenic magnetic phases in the Danube river sediments (Bulgarian part). Earth Planet. Sci. Lett. 221, 71-89.

Kim, W., Doh, S.-J., Yu, Y., Lee, Y.I., 2013. Magnetic evaluation of sediment provenance in the northern East China Sea using fuzzy c-means cluster analysis. Mar. Geol. 337, 9-19.

Kissel, C., Liu, Z., Li, J., Wandres, C., 2016. Magnetic minerals in three Asian rivers draining into the South China Sea: Pearl, Red, and Mekong Rivers. Geochem. 
Geophys. Geosyst. 17, 1678-1693.

Kissel, C., Liu, Z., Li, J., Wandres, C., 2017. Magnetic signature of river sediments drained into the southern and eastern part of the South China Sea (Malay Peninsula, Sumatra, Borneo, Luzon and Taiwan). Sediment. Geol. 347, 10-20.

Kissel, C., Sarnthein, M., Laj, C., Wang, P.X., Wandres, C., Egli, R., 2018. Magnetic fingerprints of modern sediments in the South China Sea resulting from source-to-sink processes. Geochem. Geophys. Geosyst. 19, 1979-1993.

Lei, K., Meng, W., Zheng, B., Hou, X., Sun, Y., 2007. Variations of water and sediment discharges to the western coast of Bohai Bay and the environmental impacts. Acta Sci. Circumst. 27, 2052-2059 (in Chinese with English Abstract).

Li, G., Wang, H., Liao, H., 2010. Numerical simulation on seasonal transport variations and mechanisms of suspended sediment discharged from the Yellow River to the Bohai Sea. J. Geogr. Sci. 20, 923-937.

Li, C., Yang, S., Zhang, W., 2012. Magnetic properties of sediments from major rivers, aeolian dust, loess soil and desert in China. J. Asian Earth Sci. 45, 190-200.

Li, M., Ouyang, T., Roberts, A.P., Heslop, D., Zhu, Z., Zhao, X., Tian, C., Peng, S., Zhong, H., Peng, X., Qiu, Y., 2018. Influence of sea level change and centennial East Asian monsoon variations on northern South China Sea sediments over the past $36 \mathrm{kyr}$. Geochem. Geophys. Geosyst. 19, 1674-1689.

Li, Q., Zhang, Q., Li, G., Liu, Q., Chen, M.-T., Xu, J., Li, J., 2019. A new perspective for the sediment provenance evolution of the middle Okinawa Trough since the last deglaciation based on integrated methods. Earth Planet. Sci. Lett. 582, 1-14.

Liu, Z., Xia, D., Berne, S., Wang, K., Marsset, T., Tang, Y., Bourillet, J., 1998. Tidal deposition systems of China's continental shelf, with special reference to the eastern Bohai Sea. Mar. Geol. 145, 225-253.

Liaoning Bureau of Geology and Mineral Resources, 1989. Regional Geology of Liaoning Province. Geological Publishing House, Beijing, pp. 1-856 (in Chinese with English Abstract).

Liu, Q., Roberts, A.P., Jos Eacute, T., Chorng-Shern, H., Larrasoaña, J.C., 2007. What do the HIRM and S-ratio really measure in environmental magnetism? Geochem. Geophys. Geosyst. 80, Q09011.

Liu, J., Saito, Y., Kong, X., Wang, H., Wen, C., Yang, Z., Nakashima, R., 2010. Delta development and channel incision during marine isotope stages 3 and 2 in the western South Yellow Sea. Mar. Geol. 278, 54-76.

Maher, B.A., 2007. Environmental magnetism and climate change. Contemp. Phys. 48, 247-274.

Milliman, J.D., Meade, R.H., 1983. World-wide delivery of river sediment to the oceans. The Journal of Geology 91, 1-21.

MWRC (Ministry of Water Resources of China), 2019. China river sediment bulletin 2018. China WaterPower Press, Beijing, pp. 1-69.

Oldfield, F., 1991. Environmental magnetism—a personal perspective. Quat. Sci. Rev. 10, 73-85.

Piper, J.D.A., Zhang, J., 1999. Palaeomagnetism, rock magnetism and magnetic fabrics in Precambrian metamorphic terranes of the Huabei Shield, China. J. Asian Earth Sci. 17, 395-419.

Qiao, L., Bao, X., Wu, D., 2008. The observed currents in summer in the Bohai Sea. Chin. J. Oceanol. Limnol. 26, 130-136.

Qiao, S., Shi, X., Zhu, A., Liu, Y., Bi, N., Fang, X., Yang, G., 2010. Distribution and transport of suspended sediments off the Yellow River (Huanghe) mouth and the nearby Bohai Sea. Estuar. Coast. Shelf Sci. 86, 337-344.

Qiao, S., Shi, X., Wang, G., Zhou, L., Hu, B., Hu, L., Yang, G., Liu, Y., Yao, Z., Liu, S., 2017. Sediment accumulation and budget in the Bohai Sea, Yellow Sea and East China Sea. Mar. Geol. 390, 270-281.

Qin, Y., Zhao, Y., Zhao, S., 1985. Geology of the Bohai Sea. Science Press, Beijing (in Chinese).

Ren, M., Shi, Y., Yang, J., 1986. Sediment discharge of the Yellow River (China) and its effect on the sedimentation of the Bohai and the Yellow Sea. Cont. Shelf Res. 6, 785-810.

Roberts, A.P., 1995. Magnetic properties of sedimentary greigite $\left(\mathrm{Fe}_{3} \mathrm{~S}_{4}\right)$. Earth Planet. Sci. Lett. 134, 227-236.

Roberts, A.P., Stoner, J.S., Richter, C., 1999. Diagenetic magnetic enhancement of sapropels from the eastern Mediterranean Sea. Mar. Geol. 153, 103-116.

Robinson, S.G., 1986. The late Pleistocene palaeoclimatic record of North Atlantic deepsea sediments revealed by mineral-magnetic measurements. Phys. Earth Planet. Inter. $42,22-47$

Shandong Bureau of Geology and Mineral Resources, 1991. Regional Geology of Shandong Province. Geological Publishing House, Beijing, pp. 1-595 (in Chinese with English Abstract).

Shi, X.Z., Yu, D.S., Warner, E.D., Pan, X.Z., Petersen, G.W., Gong, Z.G., Weindorf, D.C 2004. Soil database of 1:1,000,000 digital soil survey and reference system of the Chinese genetic soil classification system. Soil Survey Horizons 45, 129-135.

Su, J., 1998. Circulation dynamics of the China Seas north of $18^{\circ}$ N. In: Robinson, A.R., Brink, K. (Eds.), The Global Coastal Ocean: Regional Studies and Syntheses. John Wiley, NewYork, pp. 483-505.

Su, J., Yuan, Y., 2005. Hydrology in China Coastal Sea. Ocean Press, Beijing, pp. 1-367 (in Chinese).
Torrent, J., Liu, Q., Bloemendal, J., Barron, V., 2007. Magnetic Enhancement and Iron Oxides in the Upper Luochuan Loess-Paleosol Sequence, Chinese Loess Plateau. Soil Sci. Soc. Am. J. 71, 1570-1578.

Veneva, L., Hoffmann, V., Jordanova, D., Jordanova, N., Fehr, T., 2004. Rock magnetic, mineralogical and microstructural characterization of fly ashes from Bulgarian power plants and the nearby anthropogenic soils. Phys. Chem. Earth 29, 1011-1023.

Wang, H., 2010. Study on Eco-Environmental Pressures Assessment and their Impacts on the Coastal Zone in the Liaodong Bay. Chinese Research Academy of Environmental Sciences, Beijing (in Chinese with English Abstract).

Wang, Y., Dong, H., Li, G., Zhang, W., Oguchi, T., Bao, M., Jiang, H., Bishop, M.E., 2010a. Magnetic properties of muddy sediments on the northeastern continental shelves of China: Implication for provenance and transportation. Mar. Geol. 274, 107-119.

Wang, J., Shen, Y., Guo, Y., 2010b. Seasonal circulation and influence factors of the Bohai Sea: a numerical study based on Lagrangian particle tracking method. Ocean Dyn. 60, 1581-1596.

Wang, L., Li, J., Zhao, J., Zhai, B., 2013. Detrital minerals in the surrounding river sediments, Liaodong Bay, Bohai Sea: Composition and its geological significance. Acta Sedimentol. Sin. 31, 663-671 (in Chinese with English Abstract).

Wang, L., Li, J., Zhao, J., Dou, Y., Hu, B., Sun, R., 2014. Detrital minerals assemblages and distribution as indicators of provenance and dispersal pattern in surface sediments from Liaodong Bay, Bohai Sea. Acta Oceanol. Sin. 36, 66-74 (in Chinese with English Abstract).

Wang, S., Wang, Y., Liu, J., Yu, Y., 2015. Magnetic characteristics of surface sediments of Liaodong Bay, China. J. Ocean Univ. China 14, 407-416.

Wang, K., Shi, X., Cai, S., Qiao, S., Jiang, X., 2010c. Distribution and provenance of the surface sediments of the Yellow River mouth and Laizhou Bay deduced from heavy minerals. Marine Geology and Quaternary Geology 30, 1-8 (in Chinese with English Abstract).

Wang, Y., Wang, S., Liu, M., 2017. Magnetic properties indicate sediment provenance and distribution patterns in the Bohai and Yellow Seas, China. Cont. Shelf Res. 140, 84-95.

Xu, D., Liu, X., Zhang, X., Li, T., Chen, B., 1997. China Offshore Geology. Geology Publish House, Beijing (in Chinese).

Xue, P., Chang, L., Wang, S., Liu, S., Li, J., Shi, X., Khokiattiwong, S., Kornkanitnan, N., 2019. Magnetic mineral tracing of sediment provenance in the Central Bengal Fan. Mar. Geol. 415, 105955.

Yang, D., 2011. Analysis of Variations in Sediment Transport of Main Rivers in Yingkou Area. The Fifth water industry advanced technology forum, Beijing (in Chinese).

Yang, R.M., Li, G.X., Li, A.L., Yuan, C.T., Deng, S.G., 2005. Studies on sedimentary characteristics and process of erosion-accumulation of Guangli River mouth bar. Periodical of Ocean University of China 35, 339-343 (in Chinese with English Abstract).

Yao, Y., Zhu, H., Li, B., Hu, H., Zhang, T., Yamazaki, E., Taniyasu, S., Yamashita, N., Sun, H., 2014. Distribution and primary source analysis of per-and poly-fluoroalkyl substances with different chain lengths in surface and groundwater in two cities, North China. Ecotoxicol. Environ. Saf. 108, 318-328.

Ye, Q., 1989a. Fluvial processes of the lower Yellow River and estimation of flood conditions. In: Brush M.L., Wolman G.M., Huang, B. (Eds.), Taming the Yellow River: Silt and Floods. Springer, pp. 261-274.

Ye, Q., 1989b. Lanform system of the great plain of north China and its tendency of environmental evolution. Geogr. Res. 8, 10-20 (in Chinese with English Abstract).

Yu, Q.S., 2004. Analysis of the Silt Deposition atthe Mouth of the Zhangwei New River. Journal of Hebei Engineering Technical College 6, 15-18 (in Chinese with English Abstract).

Zalasiewicz, J., Waters, C.N., Sul, J.A.I.D., Corcoran, P.L., Barnosky, A.D., Cearreta, A., Edgeworth, M., Galuszka, A., Jeandel, C., Leinfelder, R., 2016. The geological cycle of plastics and their use as a stratigraphic indicator of the Anthropocene. Anthropocene 13, 4-17.

Zhang, J., 2000. Case analysis of the water and soil erosion in the Dayang River basin. Water Resources and Hydropower of Northeast China 35-36 (in Chinese with English Abstract).

Zhang, W., Xing, Y., Yu, L., Feng, H., Lu, M., 2008. Distinguishing sediments from the Yangtze and Yellow Rivers, China: a mineral magnetic approach. The Holocene 18, $1139-1145$.

Zhang, C., Qiao, Q., Piper, J.D.A., Huang, B., 2011. Assessment of heavy metal pollution from a Fe-smelting plant in urban river sediments using environmental magnetic and geochemical methods. Environ. Pollut. 159, 3057-3070.

Zhang, Q., Liu, Q., Li, J., Sun, Y., 2018. An integrated study of the eolian dust in pelagic sediments from the North Pacific Ocean based on environmental magnetism, transmission electron microscopy, and diffuse reflectance spectroscopy. J. Geophys. Res. Solid Earth 123, 3358-3376.

Zhao, J., Yu, Z., 2019. Characteristics analysis and countermeasures of water pollution in Chaohe River system. Water technical supervision 5, 115-117 (in Chinese).

Zhao, B., Zhuang, G., Cao, D., Lei, F., 1995. Circulation, tidal residual currents and their effects on the sedimentations in the Bohai Sea. Oceanol. Limnol. Sin. 26, 466-473 (in Chinese with English Abstract). 